\title{
EHMTI-0370. The performance of the ID-Migraine questionnaire in a Hungarian sample
}

\author{
E Csepany $^{1 *}$, M Toth $^{2}$, D Janoska ${ }^{3}$, I Kellermann ${ }^{3}$, B Hajnal $^{3}$, T Gyure $^{1}$, G Bozsik $^{4}$, C Ertsey $^{4}$ \\ From 4th European Headache and Migraine Trust International Congress: EHMTIC 2014 \\ Copenhagen, Denmark. 18-21 September 2014
}

\section{Background}

Migraine causes significant disability and severely affects patients' quality of life. A significant proportion of patients is not diagnosed, and therefore not treated adequately. A short and reliable migraine screening tool could improve disease identification. ID-Migraine is a simple and reliable screening tool, originally developed in the United States, but also used in other countries and languages.

\section{Objective}

To assess the performance of the ID-Migraine questionnaire on a Hungarian sample.

\section{Methods}

Outpatients at the Headache Service, Department of Neurology, Semmelweis University completed the Hungarian version of ID-Migraine. The gold standard was the clinical diagnosis made by a headache specialist according to the ICHD criteria. We calculated the sensitivity, specificity, positive and negative predictive value and the misclassification rate.

\section{Results}

305 patients (241 females, mean age $39,2 \pm 13,3$ years) were enrolled. The diagnosis was migraine in 244 , tension type headache in 37, cluster headache in 16 and other headaches in 8 . The questionnaire's sensitivity was 0.95 and specificity was 0.56 . The positive predictive value was 0.89 and the negative predictive value was 0.78 . The misclassification rate was 0.13 .

\section{Discussion}

The Hungarian version of ID-Migraine was easy to use and well accepted by patients. Its specificity was somewhat

'János Szentágothai Neurosciences PhD School, Semmelweis University, Budapest, Hungary

Full list of author information is available at the end of the article lower than that of the original questionnaire; its other measures of performance were similar to those of the original version and its existing Italian, Turkish and Portuguese translations. ID-Migraine seems to be a promising screening tool for migraine in the Hungarian population.

No conflict of interest.

\section{Authors' details}

'János Szentágothai Neurosciences PhD School, Semmelweis University, Budapest, Hungary. ${ }^{2}$ Headache Service, Vaszary Kolos Hospital, Esztergom, Hungary. ${ }^{3}$ Faculty of Medicine, Semmelweis University, Budapest, Hungary. ${ }^{4}$ Department of Neurology, Semmelweis University, Budapest, Hungary.

Published: 18 September 2014

doi:10.1186/1129-2377-15-S1-J3

Cite this article as: Csepany et al:: EHMTI-0370. The performance of the ID-Migraine questionnaire in a Hungarian sample. The Journal of Headache and Pain 2014 15(Suppl 1):J3.

\section{SpringerOpen ${ }^{\circ}$}

(C) 2014 Csepany et al; licensee Springer. This is an Open Access article distributed under the terms of the Creative Commons Attribution License (http://creativecommons.org/licenses/by/2.0), which permits unrestricted use, distribution, and reproduction in any medium, provided the original work is properly cited.
Submit your manuscript to a SpringerOpen ${ }^{\circ}$ journal and benefit from:

- Convenient online submission

- Rigorous peer review

- Immediate publication on acceptance

- Open access: articles freely available online

- High visibility within the field

Retaining the copyright to your article

Submit your next manuscript at $>$ springeropen.com 